\title{
STORM BEACH BUFFER REQUIREMENT FOR STORM WAVES FROM A TROPICAL CYCLONE
}

\author{
Fang-Chun Lee ${ }^{1}$, Wen-Hua Lin $^{1}$, John R.-C. Hsu ${ }^{1}$
}

\begin{abstract}
Storm beach buffer, being different from the coastal set back currently in place in many countries in the world, is the provision of a sufficient beach width to safe guard against the onslaught of a fierce storm. The extent of this requirement is tentatively assessed using the SBEACH module in the CEDAS package. The inputs for the SBEACH module include berm width, medium sand grain diameter, beach slope, design water level and wave conditions; while the outputs consist of a range of characteristic parameters for the change in beach profile, especially berm erosion and bar formation resulting from a storm of different return periods. After having systematically performed a series of numerical studies, we may conclude that: (1) Berm erosion increases and bar becomes further offshore as the storm return period increases on a beach with identical sand grain size (i.e., non-dimensional fall velocity), or as sand grain dimension reduces; (2) Higher storm waves result in a larger bar to form quicker and cause wave breaking on the bar crest which could reduce the wave energy and limit the extent of the subsequent berm erosion; (3) Empirical equations can be derived to calculate the storm beach buffer width; and (4) A larger buffer is required for a beach with smaller sand grain, in order to effectively absorb the storm wave energy. The results presented in this paper can be used to assist in a beach nourishment project for shore protection and the design of a recreational beach.
\end{abstract}

Keywords: storm beach buffer, berm erosion, bar distance offshore, storm return period, beach profile changes

\section{INTRODUCTION}

The provision of an adequate storm beach buffer is necessary for the safety of a beach during storm events and ecological conservation. A beach functions not only as the habitat for marine fauna and flora, but also for the needed protection against the onslaught of a fierce storm. During a storm, the stability of a berm, dune and associated beach profile is affected by large waves and high storm surges, resulting in permanent beach retreat if the buffer is insufficient. For example, Hurricane Bob which caused a strong northeast storm on the Halloween Eve in 1991 along Massachusetts' North and South Shores in the United States had reduced a significant portion of the beach/barrier buffer zone (Fitzgerald et al., 1994). The widespread and severe damage to the dwellings occurred along the South Shore in the areas where beaches were narrow or nonexistent and places where houses were subjected to gravel overwash. In Japan, many sections of the Ibaraki coast were once protected by sandy beaches with dunes, but were eroded after port construction; thus reducing the beach width from a few hundred meters to a few ten meters. Consequently, storm waves and severe surges broke seawalls and cut sand dunes, during typhoon Bebeica event in October, 2006, despite the existence of protective hard structures (Hisamichi, 2008).

Nowadays, artificial nourishment schemes incorporating man-made headlands have been carried out in many countries for the design of recreational beach and shore protection. The performance of such a scheme depends on the duration (or longevity) of the fill material to be retained on the new beach. On a beach frequented by storms, the extra volume of new sediment on an existing beach offers better protection against the onslaught of a fierce storm. Hanson et al. (2002), among many others, have reported several successful coastal projects with artificial nourishment in Europe. In Taiwan, nourishment projects were executed at Anping during 2002 2004 and Sizihwan between 2006 2008. Both are in the southwestern Taiwan, where artificial beach was produced by nourishment incorporating man-made headlands of groin type, from dredged navigation channel and offshore site, respectively. After several storm events, both sites had experienced beach retreat in the middle of the embayment (see Fig. 1), due to insufficient storm buffer width.

In addition, for an artificially nourished beach incorporating man-made headlands, sufficient berm width should be taken to delineate the shoreline planform in static equilibrium in order to ensure the safety of a beach during a storm, in addition to the simultaneous requirement of the equilibrium beach profile (EBP). To accomplish this objective, the headland tip should be located preferably beyond the distance of bar position that could exist. The aim of this paper is to discuss the need and quantification of adequate berm width for a design storm of assumed return period in order to mitigate local beach erosion. The preliminary results derived from a series of numerical computations using the SBEACH

\footnotetext{
${ }^{1}$ Department of Marine Environment and Engineering, National Sun Yat-sen University, 70 Lien-hai Road, Kaohsiung 80424, Taiwan, R.O.C.
} 
model are then presented, with special focus on the variations in berm retreat and bar location for a beach with different medium grain sizes and the storm return periods.
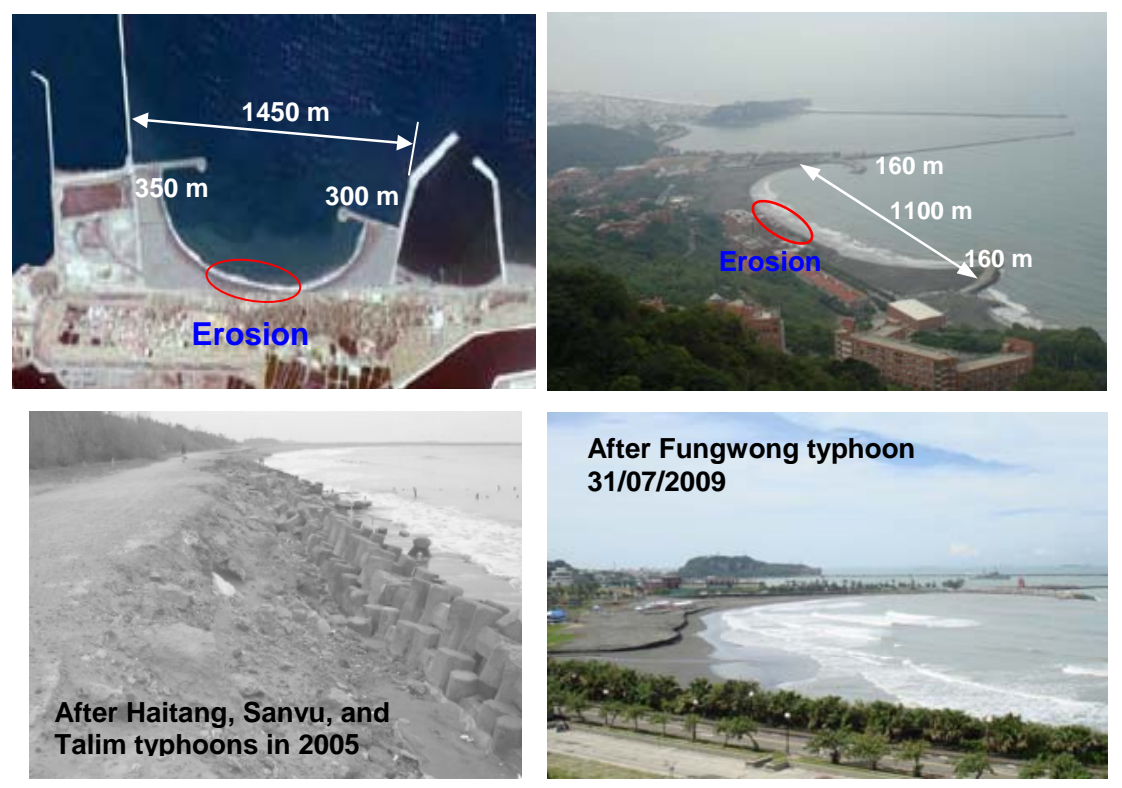

Fig. 1 Anping (2005) and Sizihwan (2008) coast in SW Taiwan.

\section{DEFINITION OF STORM BUFFER WIDTH}

In some countries, "storm buffer" has been defined as "coastal zone” or part of "coastal protection zone" landward to meet different purposes. For example, an extent of $50 \mathrm{~m}$ to $3 \mathrm{~km}$ landward from the shoreline has been taken in Germany, Denmark, Estonia, Sweden and Finland (MAECOP, 2009). In this study, we restrict our discussion to the storm buffer width $(X)$ on beach berm and dune, from the original shoreline $\left(X_{s}\right)$ to the maximum berm retreat $\left(X_{b}\right)$ in Fig. 2.

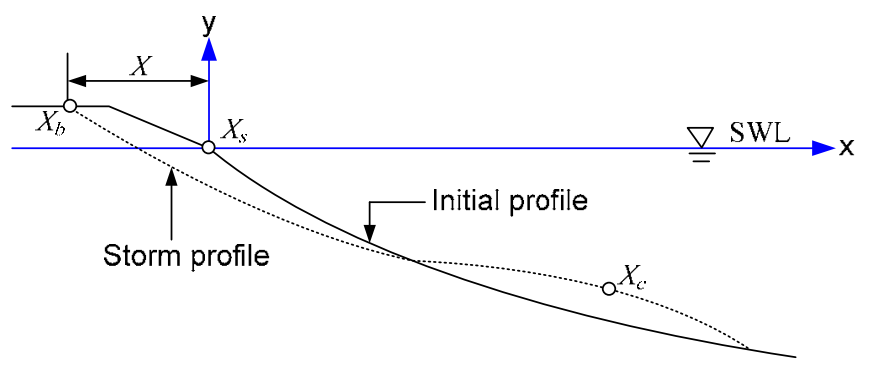

Fig. 2 An idealized schematic definition of storm beach buffer width $X$.

\section{SBEACH AND MODEL CALIBRATION}

SBEACH (Storm-induced BEAch CHange) is the most well known tool for assessing beach profile changes. It has been promoted by Veri-Tech, Inc. in the United States as a module within the CEDAS (Coastal Engineering Design and Analysis System, version 4.03) package after Kraus and Larson (1988) and Larson et al. (1990). This numerical model is based on the re-analysis of laboratory data conducted in large wave tank (LWT) in the United States during 1956-1957 and 1962, and the correlation between prevailing wave conditions and temporal variation in beach profile. Based on the nearshore wave dynamics and the physical characteristics of sediment transport under various flow conditions and nearshore bathymetry, a beach profile is divided into four distinctive zones (Fig. 3, Larson et al., 1990):

1. Zone I: From the seaward depth of effective sand transport to the breaker point (pre-breaking zone).

2. Zone II: From the break point to the plunge point (breaker transition zone). 
3. Zone III: From the plunge point to the point of wave reformation or to the swash zone (broken wave zone).

4. Zone IV: From the shoreward boundary of the surf zone to the shoreward limit of runup (swash zone).

The transport rate in each zone, based on physical considerations and reanalysis of the LWT data, are given by (Larson et al., 1990):

$$
\begin{aligned}
& \text { Zone I : } q=q_{b} e^{-\lambda_{1}\left(x-x_{b}\right)} \quad x_{b}<x \\
& \text { Zone II : } q=q_{p} e^{-\lambda_{2}\left(x-x_{p}\right)} \quad x_{p}<x \leq x_{b}
\end{aligned}
$$

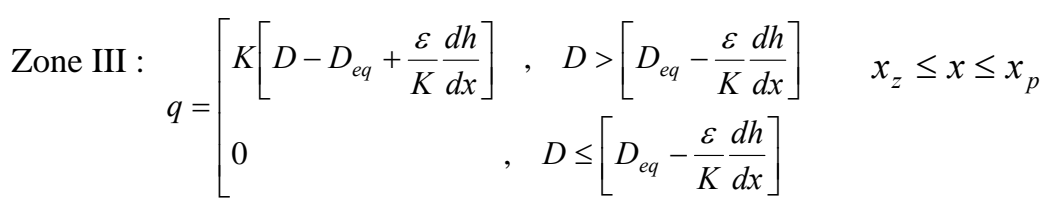

$$
\begin{aligned}
& \text { Zone IV : } q=q_{z}\left[\frac{x-x_{r}}{x_{z}-x_{r}}\right] \quad x_{r}<x<x_{z}
\end{aligned}
$$

where $q\left(\mathrm{~m}^{3} / \mathrm{m}\right.$-sec) is the net cross-shore sand transport rate, $\lambda_{1}$ and $\lambda_{2}(\mathrm{l} / \mathrm{m})$ are spatial decay coefficients in Zones I and II, respectively, $x(\mathrm{~m})$ is cross-shore coordinate with positive offshore, $K$ $\left(\mathrm{m}^{4} / \mathrm{N}\right)$ is a sand transport rate coefficient, $D\left(\mathrm{~N}-\mathrm{m} / \mathrm{m}^{3}-\mathrm{sec}\right)$ wave energy dissipation per unit water volume, $D_{e q}\left(\mathrm{~N}-\mathrm{m} / \mathrm{m}^{3}\right.$-sec) the equilibrium energy dissipation per unit water volume, $\varepsilon\left(\mathrm{m}^{2} / \mathrm{sec}\right)$ a slope-related sand transport rate coefficient, and $h(\mathrm{~m})$ the still-water depth. The subscripts $b, p, z$, and $r$ stand for the quantities evaluated at the break point, plunge point, end of the surf zone, and runup limit, respectively. Different spatial decay coefficients are used in Zones I and II, denoted by subscripts 1 and 2, to differentiate the decrease in sand transport rate with distance.

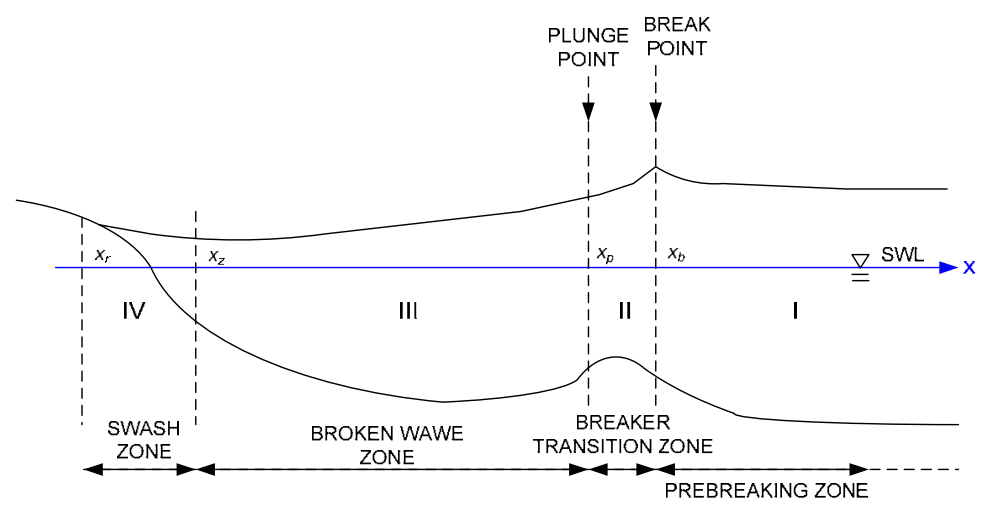

Fig. 3 Principal zones of cross-shore transport (Larson et al., 1990)

We first examine the effects of the two principal parameters (i.e., transport rate coefficient, $K$, and the slope-related sand transport coefficient, $\varepsilon$ ) on beach profile changes. The procedure involves the comparison of the entire profiles derived from the simulation using SBEACH with that measured from the selected LWT cases cited in Kraus and Larson (1988).

The relative error in each final beach profile between these two sources is defined as:

$$
\sigma=\left\{\sum_{x=0}^{N}\left[\frac{\left(y_{S B E A C H}-y_{L W T}\right)^{2}}{y_{L W T}^{2}}\right]\right\}^{1 / 2}
$$

where $y_{S B E A C H}$ and $y_{L W T}$ are the simulated and laboratory result under monochromatic waves, respectably; $N$ is the total number of points along a beach profile at the interval of $1.0 \mathrm{~m} ; \sigma$ is the normalized relative error representing the variation between the simulated and measured profile over $N$ sections along a beach profile. Fig. 4 depicts the variation in the relative error on transport rate 
coefficient, $K$ and slope-related sand transport coefficient, $\varepsilon$, for case CE300 obtained by Coastal Engineering Research Center (CERC) in 1956 (Kraus and Larson, 1988). The resultant beach profiles given by SBEACH and LWT for case CE300 are shown in Fig. 5, based on the best combination of $K=1.25 \times 10^{-6}\left(\mathrm{~m}^{4} / \mathrm{N}\right)$ and $\varepsilon=0.001\left(\mathrm{~m}^{2} / \mathrm{sec}\right)$ which gives the minimum normalized standard error and the best agreement on beach profiles between $y_{S B E A C H}$ and $y_{L W T}$. The same calibration procedure is applied to CE100, CE400 and CE500, each best fitted with a combination of $K$ and $\varepsilon$ values. Table 1 summarized the results of parameter calibration and input data for the four selected CE cases mentioned, as well as other relevant parameters used in running the SBEACH.

Fig. 6 displays the relationship between the best combination of coefficients $K$ and $\varepsilon$ versus nondimensional fall velocity, $H_{0} / \omega T$, for the four CE cases listed in Table 1 . The shaded area in each subplot is the applicable range of $K$ and $\varepsilon$ in applying SBEACH recommended by Larson et al., (1990). From the results of $K$ and $\varepsilon$ shown in this figure, it is apparent that $K$ increases as $H_{0} / \omega T$ increases from 4.03 (CE100) to 9.0, and then decreases when $H_{0} / \omega T \leq 9$. On the contrary, $\varepsilon$ decreases within $H_{0} / \omega T \leq 9$, and then increases as $H_{0} / \omega T>9$. Therefore, the value of $K$ and $\varepsilon$ compensate each other.

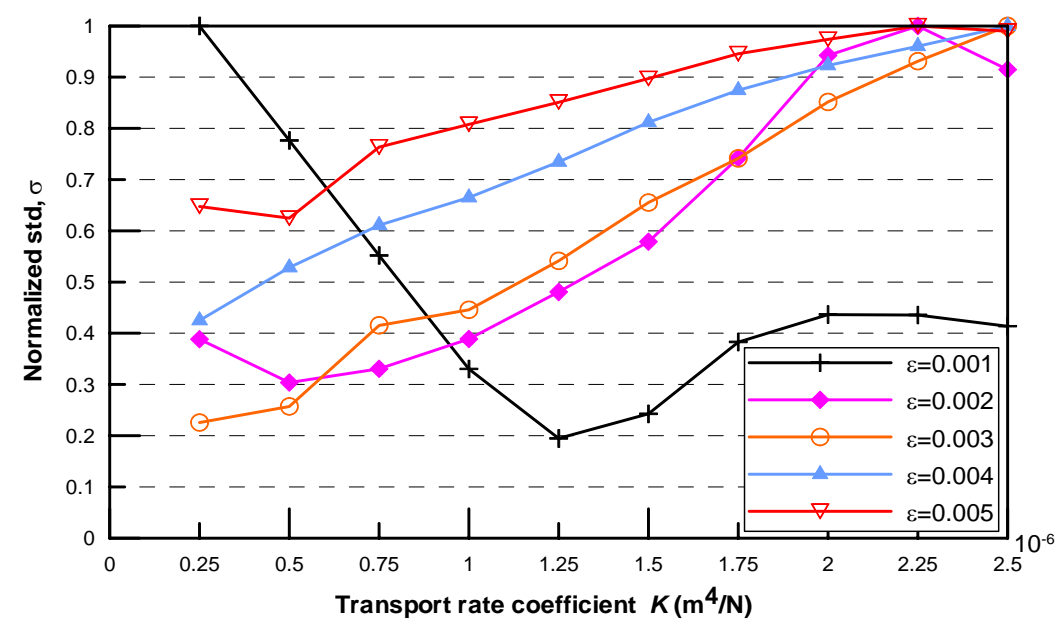

Fig. 4 Relative error in beach profile calibration from various combinations of $K$ and $\varepsilon$ Case CE300.

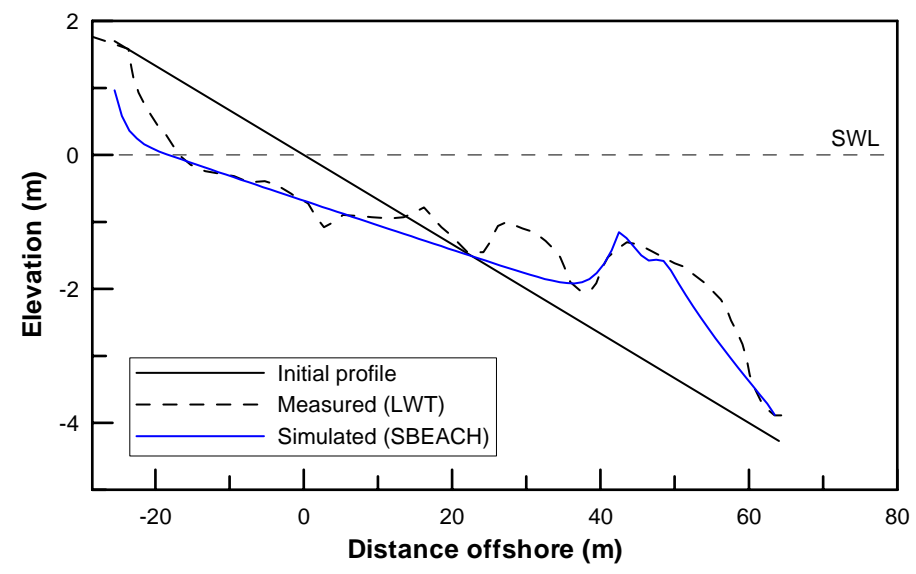

Fig. 5 Comparison on beach profiles between simulated and measured for case CE300. 

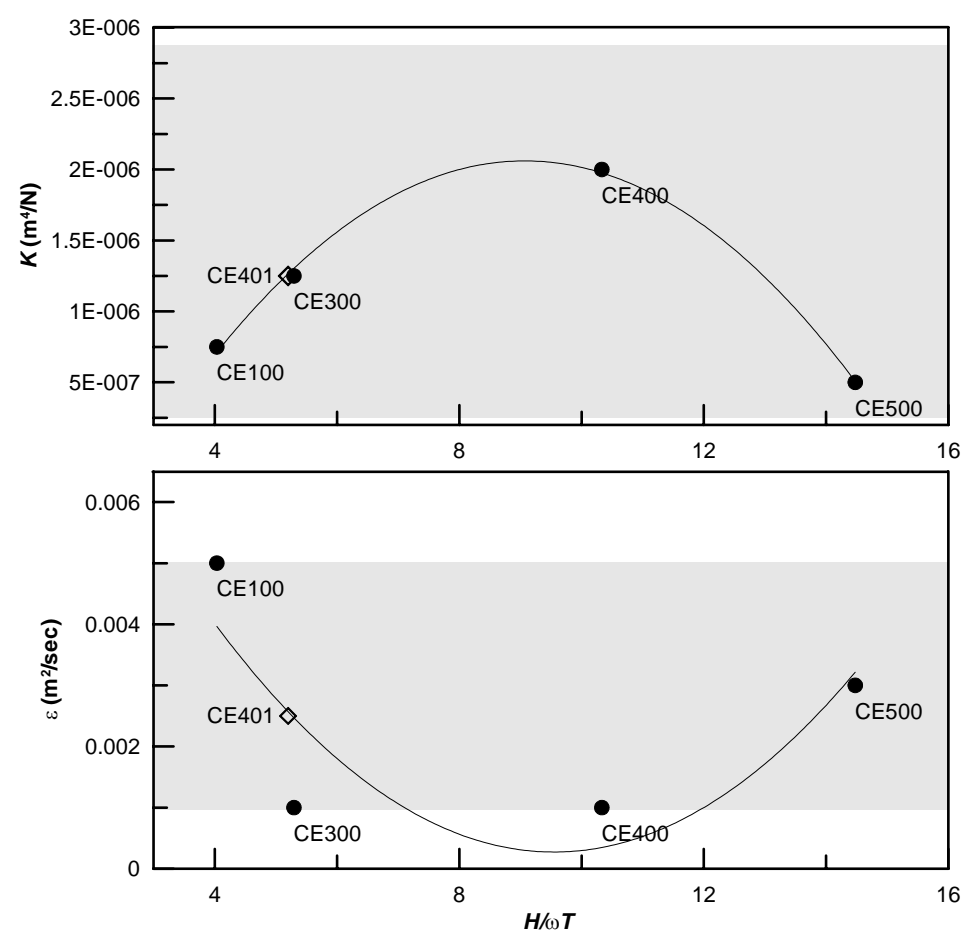

Fig. 6 Best combination of $K$ and $\varepsilon$ for each of the four selected CERC cases.

\begin{tabular}{|l|l|l|l|l|}
\hline Table 1 Input data and parameter calibration for CERC cases using SBEACH \\
\hline Case & CE100 & CE300 & CE400 & CE500 \\
\hline Initial profile & $1: 15$ & $1: 15$ & $1: 15$ & $1: 15$ \\
\hline Wave height, $H(\mathrm{~m})$ & 1.28 & 1.68 & 1.62 & 1.52 \\
\hline Wave period, $T(\mathrm{sec})$ & 11.33 & 11.33 & 5.60 & 3.75 \\
\hline Wave steepness, $H_{0} / L_{0}$ & 0.0054 & 0.0070 & 0.0331 & 0.0750 \\
\hline Water level $(\mathrm{m})$ & 4.57 & 4.27 & 4.42 & 4.57 \\
\hline Run time $(\mathrm{hr})$ & 36 & 50 & 43 & 100 \\
\hline Sand grain $D_{5} 0(\mathrm{~mm})$ & 0.22 & 0.22 & 0.22 & 0.22 \\
\hline Non-dimensional fall velocity, $H_{0} / \omega T$ & 4.03 & 5.30 & 10.33 & 14.48 \\
\hline Transport rate coefficient, $K\left(\mathrm{~m}^{4} / \mathrm{N}\right)$ & $7.5 \mathrm{e}-7$ & $1.25 \mathrm{e}-6$ & $2 \mathrm{e}-6$ & $5 \mathrm{e}-7$ \\
\hline Slope-related sand transport coefficient, $\varepsilon\left(\mathrm{m}^{2} / \mathrm{sec}\right)$ & 0.005 & 0.001 & 0.001 & 0.003 \\
\hline Standard error, $\sigma$ & 0.76 & 0.19 & 0.19 & 0.53 \\
\hline
\end{tabular}

\section{MODELING PROCEDURE}

A storm-built beach profile may result by storm action on an initial EBP in the form of $h=A x^{2 / 3}$ as given by Bruun (1954) and Dean (1997). In this expression, $h(\mathrm{~m})$ is the depth from a reference sealevel, and $x$ is the distance offshore. $A\left(=0.067 \omega^{0.44}\right)$ is the dimensional shape factor (Dean, 1997), where the fall velocity $\omega$ is related to a sediment grain size $\left(D_{50}\right)$, which in turn affects the berm slope and nominal sediment fall velocity as shown in Fig. 7 (data from Wiegel, 1965). From this, the value for the dimensionless fall velocity, $H_{0} / \omega T$, can be calculated. 


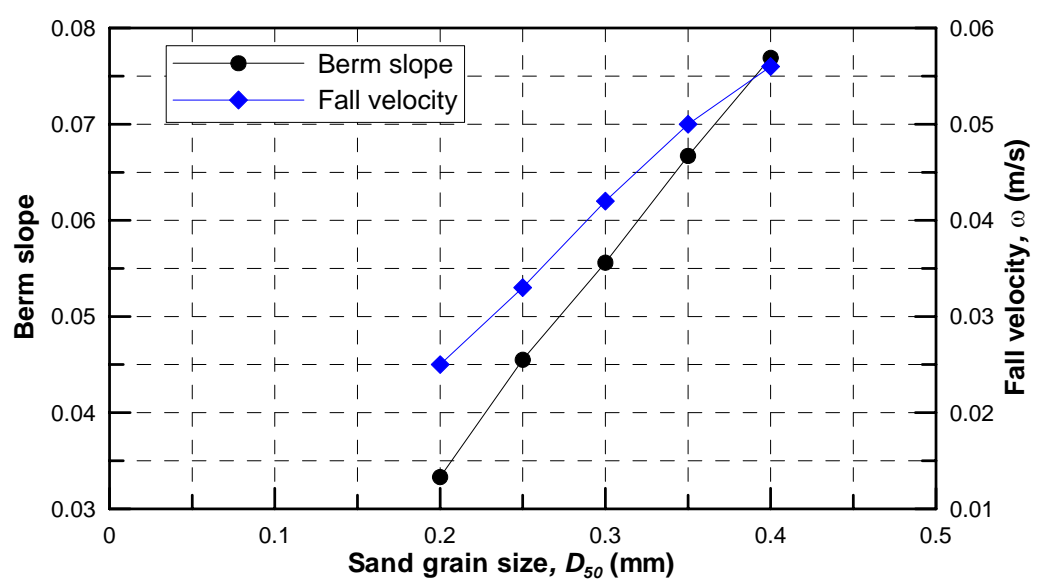

Fig. 7 Berm slope and sediment fall velocity for a given grain size.

In this study, the storm wave conditions for modeling beach profile changes in the SBEACH are derived from one of the main typhoon routes that have affected the southwestern Taiwan, from an offshore site at depth of -25 m with three different return periods during 1940 to 2005 (Table 2). The major wave approaching directions for this region were between NNW and SSW, with the most influential waves from SW and SSW quarters (Fig. 8), because the local shoreline aligns in NNW direction. In addition, storm surge caused by strong low atmospheric pressure during a storm event could increase the mean sea level by $1 \mathrm{~m}$ approximately in height, which is the extra height to be included in the design water level. Table 3 shows the design water level for modeling different storm intensities for this region in Taiwan.
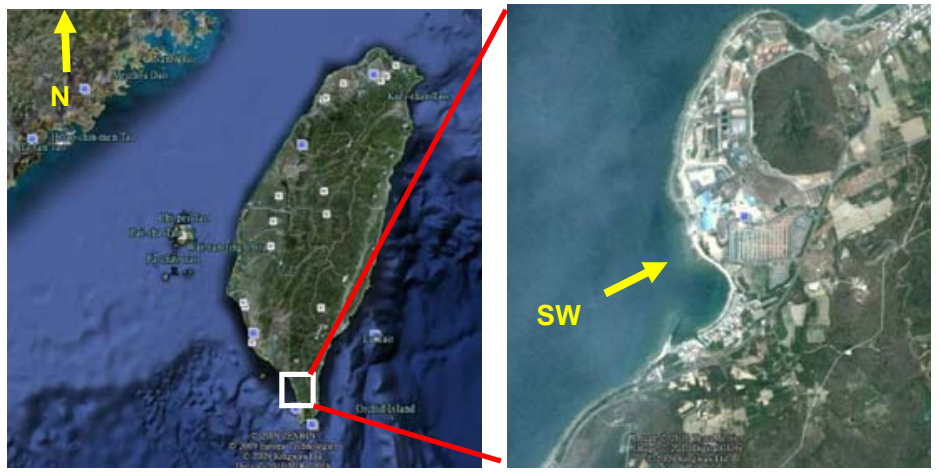

Fig. 8 Major storm wave direction at Houwan in SW Taiwan (Courtesy of Google Earth imagery)

\begin{tabular}{|c|c|c|c|c|c|c|}
\hline \multicolumn{7}{|c|}{$\begin{array}{l}\text { Table } 2 \text { Local offshore wave conditions in SW Taiwan derived from storm } \\
\text { with different return periods }\end{array}$} \\
\hline \multirow{2}{*}{$\begin{array}{ll}\text { Return period } \\
\text { Wave Direction }\end{array}$} & \multicolumn{2}{|c|}{10 years } & \multicolumn{2}{|c|}{20 years } & \multicolumn{2}{|c|}{50 years } \\
\hline & $\begin{array}{l}\mathrm{H}_{1 / 3} \\
(\mathrm{~m})\end{array}$ & $\begin{array}{l}\mathrm{T}_{1 / 3} \\
(\mathrm{sec})\end{array}$ & $\begin{array}{l}\mathrm{H}_{1 / 3} \\
(\mathrm{~m})\end{array}$ & $\begin{array}{l}T_{1 / 3} \\
(\mathrm{sec})\end{array}$ & $\begin{array}{l}\mathrm{H}_{1 / 3} \\
(\mathrm{~m})\end{array}$ & $\begin{array}{l}\mathrm{T}_{1 / 3} \\
(\mathrm{sec})\end{array}$ \\
\hline NNW & 1.6 & 5.9 & 1.9 & 6.9 & 2.3 & 8.1 \\
\hline NW & 2.9 & 8.6 & 3.4 & 9.1 & 3.9 & 9.6 \\
\hline WNW & 4.1 & 8.3 & 4.7 & 8.5 & 5.4 & 8.7 \\
\hline W & 5.0 & 9.6 & 5.8 & 9.9 & 6.6 & 10.1 \\
\hline WSW & 5.6 & 10.9 & 6.8 & 11.6 & 8.2 & 12.4 \\
\hline SW & 6.6 & 10.7 & 8.0 & 11.1 & 9.9 & 11.6 \\
\hline SSW & 7.1 & 11.9 & 8.5 & 12.6 & 10.2 & 13.2 \\
\hline
\end{tabular}




\begin{tabular}{|l|l|l|l|l|}
\hline \multicolumn{3}{|l|}{ Table 3 Design water level for modeling a typhoon event in SW Taiwan } \\
\hline $\begin{array}{l}\text { Return } \\
\text { period }(\mathrm{Yr})\end{array}$ & Tidal type & $\begin{array}{l}\text { Tide level } \\
(\mathrm{m})\end{array}$ & Storm surge $(\mathrm{m})$ & $\begin{array}{l}\text { Design water level } \\
(\mathrm{m})\end{array}$ \\
\hline \multirow{3}{*}{10} & & +0.29 & \multirow{3}{*}{0.89} & 1.18 \\
\cline { 2 - 3 } & M.W.L & +0.69 & 1.69 \\
\cline { 2 - 3 } & H.W.O.S.T. & +0.80 & & 2.18 \\
\cline { 2 - 3 } & H.H.T. & +1.29 & \multirow{3}{*}{0.98} & 1.27 \\
\hline \multirow{3}{*}{50} & M.W.L. & +0.29 & 1.75 \\
\cline { 2 - 3 } & H.W.O.S.T. & +0.80 & & 2.27 \\
\cline { 2 - 3 } & H.H.T. & +1.29 & \multirow{3}{*}{1.10} & 1.39 \\
\hline \multirow{3}{*}{50} & M.W.L & +0.29 & 1.90 \\
\cline { 2 - 3 } & H.W.O.S.T. & +0.80 & & 2.39 \\
\cline { 2 - 3 } & H.H.T. & +1.29 & &
\end{tabular}

Using a typical beach profile (berm height $2.5 \mathrm{~m}$ with width $100 \mathrm{~m}$ ) and the typhoon wave conditions given in Table 2, SBEACH model was then used to calculate the beach profile changes under monochromatic waves. Specific attention was given to berm erosion and bar location, for a design storm with different return periods, sand grain diameter and beach slope.

In the numerical calculations for a storm event with 50-year return period on a beach with $D_{50}=$ $0.25 \mathrm{~mm}$, the temporal output from SBEACH model (Fig. 9) indicates that the berm was eroded rapidly within the first 9 hours but held back for a short while about 3 hrs between $9^{\text {th }} \sim 12^{\text {th }}$ hrs, then followed by two cycles of moderate erosion, before reaching a final asymptote of berm erosion after the $39^{\text {th }}$ hrs. While the berm was experiencing erosion and eventually reaching a limit as indicated in this figure, the water depth on the bar crest decreased progressively and became steady afterward. It is suspected that, between the $39^{\text {th }}$ and $60^{\text {th }}$ hrs, material to build up the bar may come from the region between the bar and the newly eroded shoreline, rather from further berm erosion. As seen in Fig. 9, berm erosion and bar depth increase with the duration of storm action. However, calculation is terminated when berm erosion ceases or bar depth reaches a constant value. In this particular case, the total run time of 48 hours may be taken as the effective duration for the storm action on the beach.

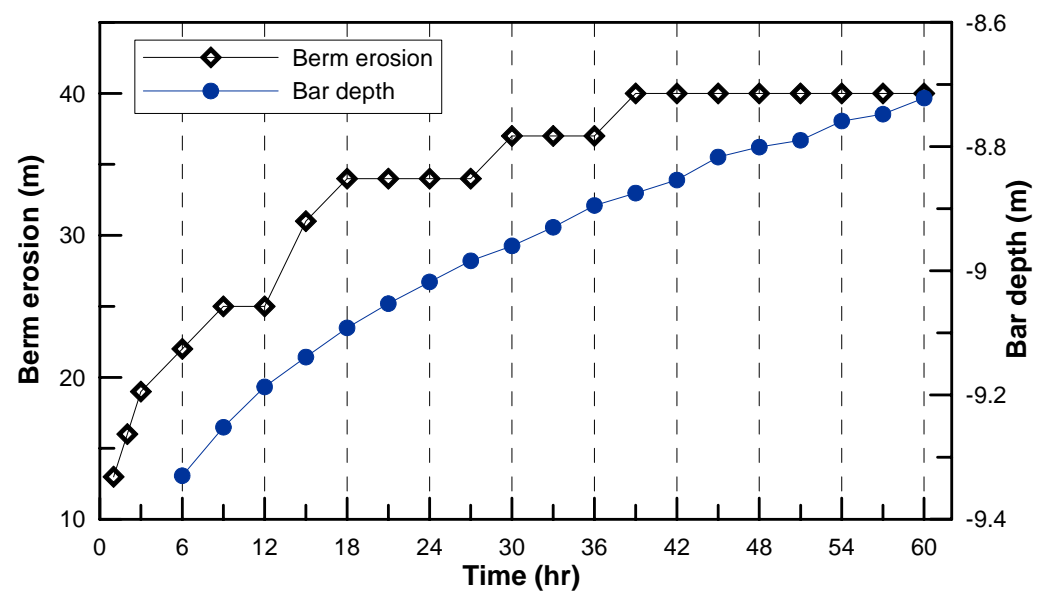

Fig. 9 Temporal variations in bar crest depth and berm erosion induced by storm waves of 50 -year return period.

\section{BERM EROSION AND BAR LOCATION}

\section{Effect of storm return period}

SBEACH model is used to simulate beach profile changes for storm waves with different return periods (10, 20 and 50 years, respectively) on a sandy beach with $D_{50}=0.25 \mathrm{~mm}$ and a constant mean sea level. From the variation in the resulting dimensionless berm erosion $\left(X_{b} / L_{0}\right)$ versus dimensionless fall velocity $H_{0} / \omega T$ for different storm return periods shown in Fig.10, the worst berm erosion $\left(X_{b} / L_{0}\right)$ appear to occur for storm with 50-year return period with wave from all possible directions. 


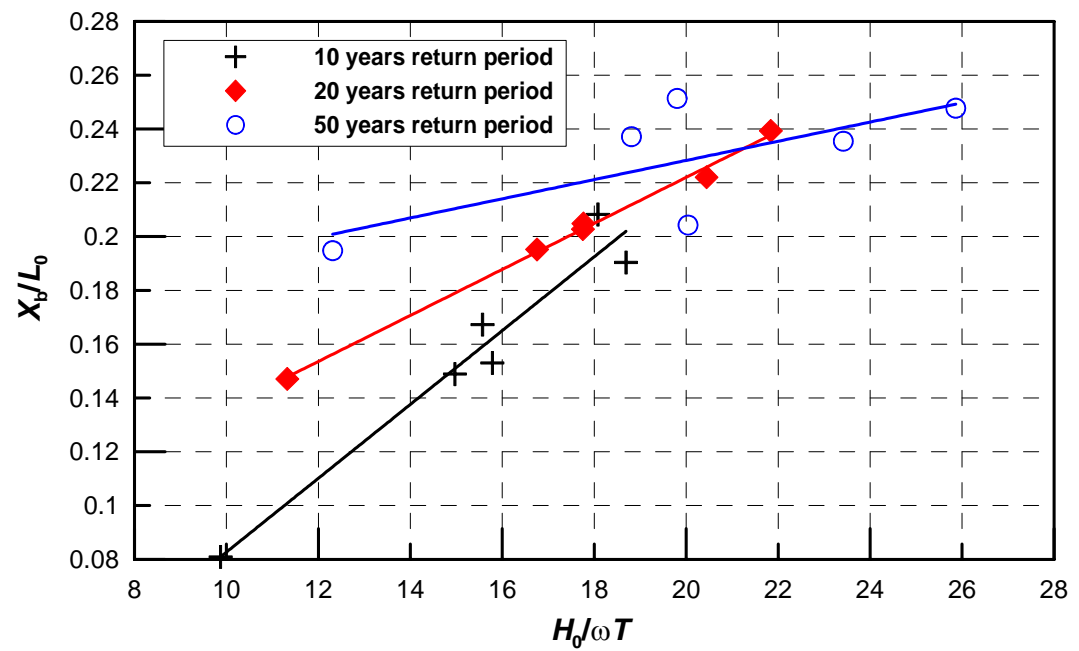

Fig. 10 Berm erosion $X_{b} / L_{0}$ versus $H_{0} / \omega T$ for storm waves with different return periods on a sandy beach.

On the other hand, dimensionless bar crest location is plotted against dimensionless fall velocity in Fig. 11, for three different storm return periods. The results suggest a positive correlation between these parameters for all three storm return periods. Moreover, despite the difference in storm return periods, a bar may be constructed further offshore as $H_{0} / \omega T$ increases, for a beach with specific $D_{50}$ or for a beach with finer sediment receiving identical wave conditions.

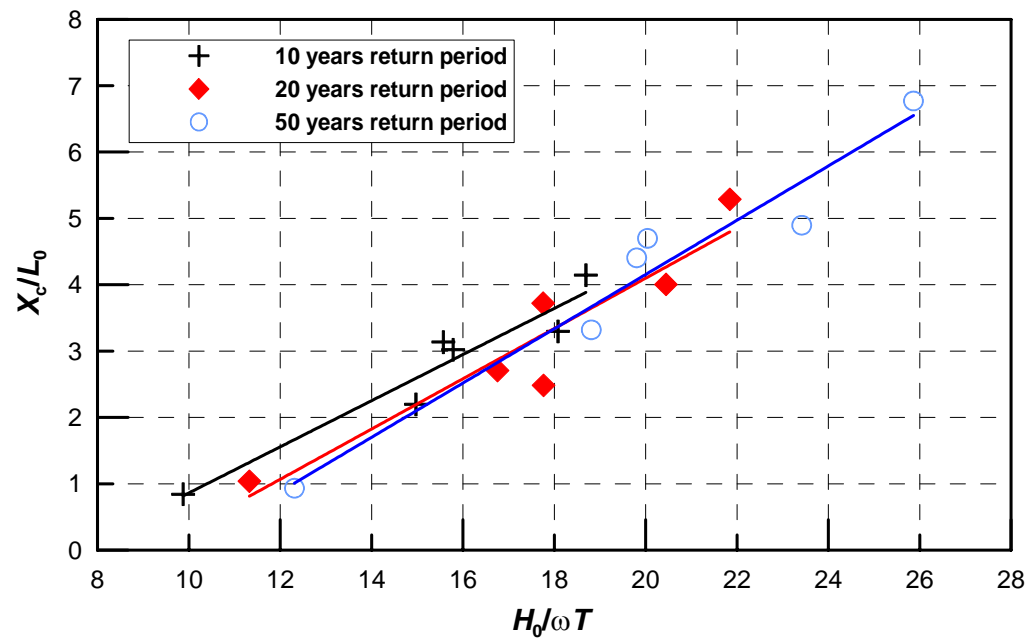

Fig. 11 Bar crest location $X_{c} / L_{0}$ versus $H_{0} / \omega T$ for storm waves with different return periods.

Table 4 summarizes the regressed equations for berm erosion $\left(X_{b} / L_{0}\right)$ and bar crest location ( $\left.X_{c} / L_{0}\right)$ as a function of $H_{0} / \omega T$ for different storm return periods. From these equations, berm erosion and bar crest location could be estimated for a given wave condition (height $H$, period $T$ ) and fall velocity $\omega$ (from $D_{50}$, see Fig. 7). 


\begin{tabular}{|c|c|c|c|}
\hline Type & $\begin{array}{l}\text { Storm return period } \\
(\mathrm{Yr})\end{array}$ & Regressed equation & $R^{2}$ \\
\hline \multirow{3}{*}{$\begin{array}{l}\text { Berm } \\
\text { erosion }\end{array}$} & 10 & $\frac{X_{b}}{L_{0}}=0.014 \frac{H_{0}}{\omega T}-0.055$ & 0.95 \\
\hline & 20 & $\frac{X_{b}}{L_{0}}=0.009 \frac{H_{0}}{\omega T}+0.051$ & 0.99 \\
\hline & 50 & $\frac{X_{b}}{L_{0}}=0.004 \frac{H_{0}}{\omega T}+0.157$ & 0.50 \\
\hline \multirow{3}{*}{$\begin{array}{c}\text { Bar } \\
\text { location }\end{array}$} & 10 & $\frac{X_{c}}{L_{0}}=0.35 \frac{H_{0}}{\omega T}-2.62$ & 0.92 \\
\hline & 20 & $\frac{X_{c}}{L_{0}}=0.38 \frac{H_{0}}{\omega T}-3.48$ & 0.89 \\
\hline & 50 & $\frac{X_{c}}{L_{0}}=0.41 \frac{H_{0}}{\omega T}-4.03$ & 0.95 \\
\hline
\end{tabular}

\section{Effect of sand grain size}

The dimension of sand grain size on a beach affects berm slope and subsequent profile changes under variable wave actions. For example, the simulated results for berm erosion $X_{b} / L_{0}$ (Fig. 12) indicate that a beach responds differently with $D_{50}$ varying from 0.2 to $0.4 \mathrm{~mm}$, under the same condition of mean sea level and 20-year storm return period. The dimensionless berm erosion $X_{b} / L_{0}$ varies not only implicitly with $H_{0} / \omega T$, but also explicitly with $D_{50}$.

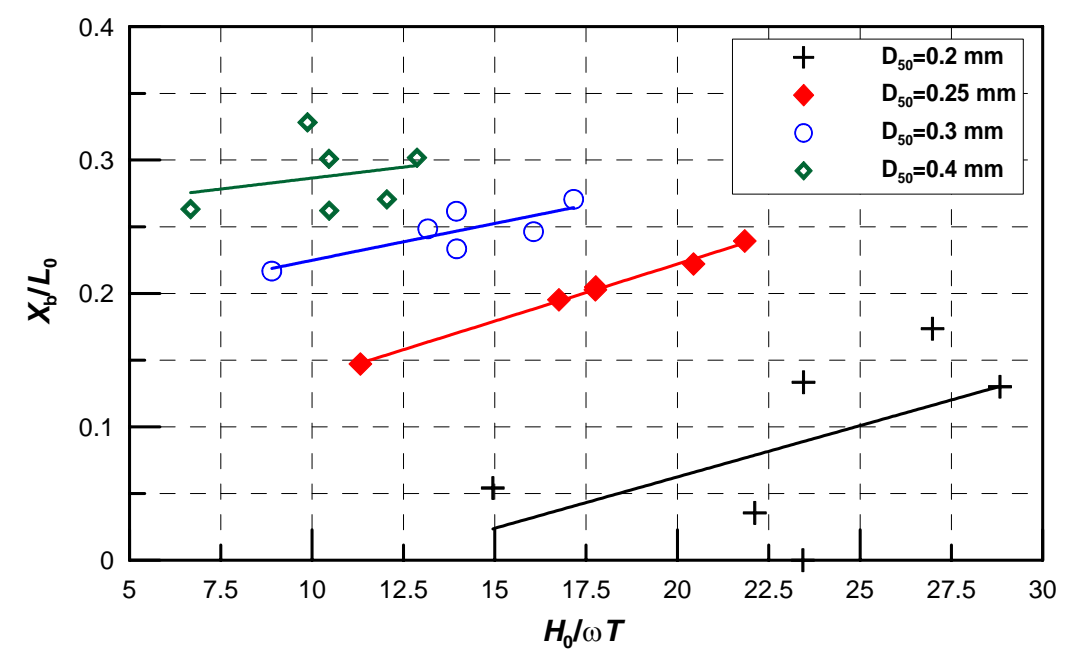

Fig. 12 Berm erosion $X_{b} / L_{0}$ versus $H_{0} / \omega T$ for beach with different $D_{50}$.

The relationship between bar crest location $X_{c} / L_{0}$ and $H_{0} / \omega T$ for different values of $D_{50}$ also reveals a consistent positive trend (Fig. 13). This implies that bar crest location increases (i.e. further offshore) as $H_{0} / \omega T$ increases for all the four $D_{50}$ values under consideration. 


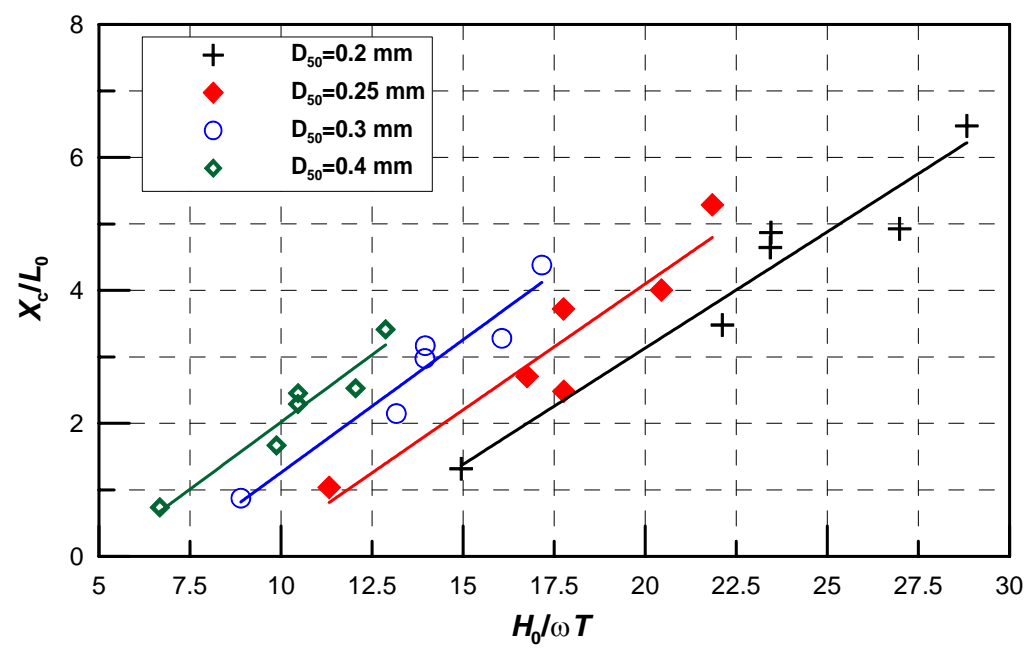

Fig. 13 Bar crest location $X_{c} / L_{0}$ versus $H_{0} / \omega T$ for beach with different $D_{50}$.

\section{Effect of tidal level}

Again, SBEACH model is used to simulate beach profile changes under the storm action associated with three tidal levels (MWL, HWOST, and HHWL) on a sandy beach with $D_{50}=0.25 \mathrm{~mm}$ and 20- year storm return period. From the variation in dimensionless berm erosion $\left(X_{b} / L_{0}\right)$ versus $H_{0} / \omega T$ for different tidal levels shown in Fig.14, the worst berm erosion $\left(X_{b} / L_{0}\right)$ occurs for storm with HHWL.

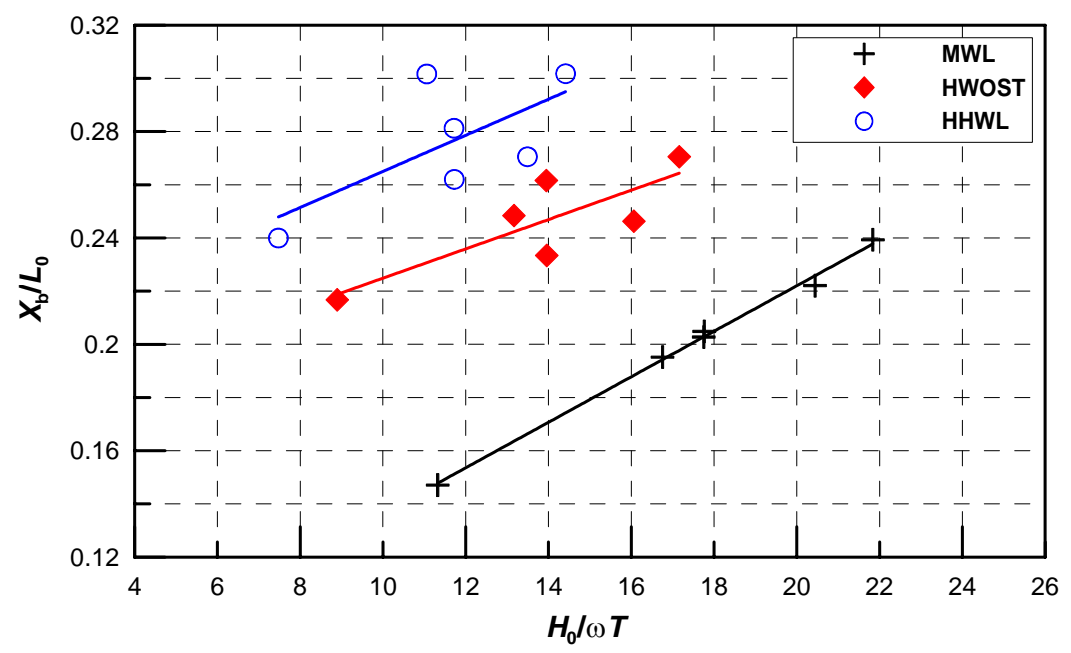

Fig. 14 Berm erosion $X_{b} / L_{0}$ versus $H_{0} / \omega T$ as a function of tidal level for beach with $D_{50}=0.25 \mathrm{~mm}$ and 20year storm return period.

Similarly, dimensionless bar location can also be related to dimensionless fall velocity (in Fig. 15), for three different tidal levels. It is obvious that bar could be constructed further offshore as $H_{0} / \omega T$ increases, for different tidal levels with $D_{50}=0.25 \mathrm{~mm}$ and 20-year storm return period. 


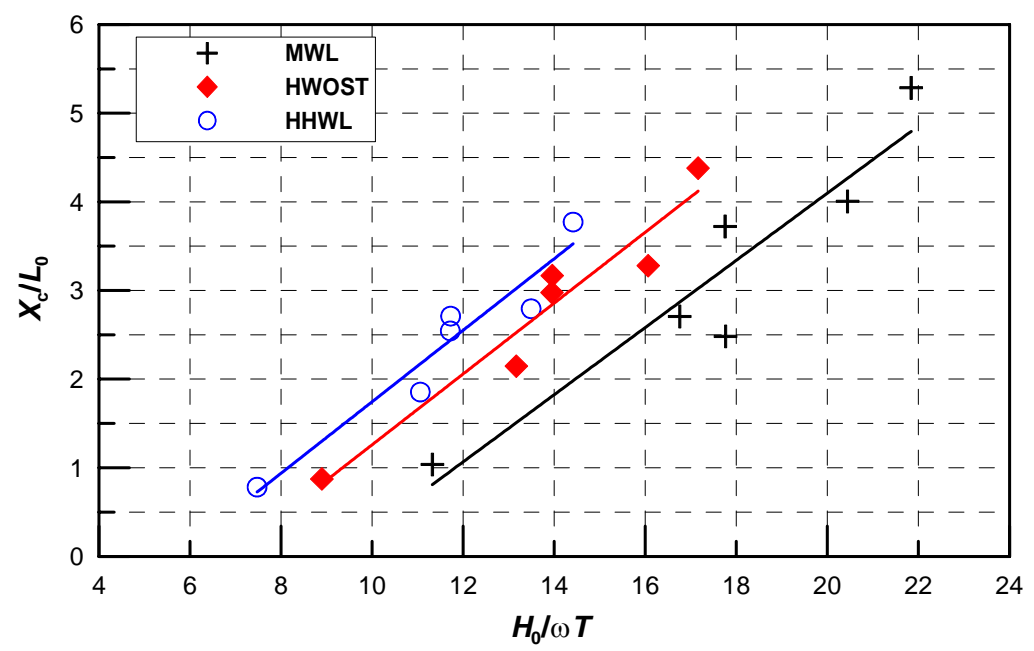

Fig. 15 Bar crest location $X_{c} / L_{0}$ versus $H_{0} / \omega T$ as a function of tidal level for beach with $\boldsymbol{D}_{50}=\mathbf{0 . 2 5} \mathbf{~ m m}$ and 20-year storm return period.

\section{APPRAISAL OF STORM BUFFER WIDTH USING SBEACH}

Since it is a common belief that a wide sandy beach is the most effective wave energy absorber for shore protection, the question is how to determine an adequate storm buffer, in order to protect the beach. For places without storm attack, berm erosion would never become a problem. On the other hand, berm erosion varies with storm wave conditions arising from different return periods, which is the most influential factor for the appraisal of storm buffer width for a beach with a specific $D_{50}$. Based on the results of a series of numerical calculations, a regressed equation for storm buffer width ( $X$ in Fig. 2) may be expressed by a multiple linear regression model:

$$
\frac{X}{H_{0}}=60.89-1.32 \frac{H_{0}}{\omega T}-43.80 \frac{\omega^{2}}{g D_{50}} \quad R^{2}=0.77
$$

Eq. (6) may be used to estimate the storm buffer from a given set of inputs values ( $H_{0}(\mathrm{~m}), T$ (sec) , $D_{50}(\mathrm{~mm})$ and $\left.\omega(\mathrm{m} / \mathrm{s})\right)$ directly. The result suggests $X / H_{0}$ value decreases either as $H_{0} / \omega T$ increases under a specific $D_{50}$ or as the $D_{50}$ increases under the same wave conditions $\left(H_{0}\right.$ and $\left.T\right)$. One possible reason is perhaps due to the wave would have broken on the bar crest accompanying by wave energy dissipation, thus limiting further berm erosion in the lee of the bar. It also implies that a wider storm buffer is required for a beach with smaller $D_{50}$. Verification using field data has also shown to be satisfactory.

\section{CONCLUSION}

This paper presents the results of modeling beach profile changes using the well-known SBEACH module. After the successful calibration of four selected beach profiles in CERC's LWT tests (Kraus and Larson, 1988), upon matching the characteristic features of the entire profile changes (especially berm erosion and bar shape), the best combination of the two key parameters (sand transport rate coefficient, $K$ and slope-related sand transport coefficient, $\varepsilon$ ) for other cases can be estimated using similar procedure from given input conditions (i.e., storm waves $\left(H_{0}\right.$ and $\left.T\right)$ for a specific return period, $D_{50}$ and design water level).

After having performed a series of numerical study, regression equations are then proposed for the appraisal of storm beach buffer width as a function of wave conditions $\left(H_{0}\right.$ and $\left.T\right)$ and medium grain size $\left(D_{50}\right.$, fall velocity $\left.\omega\right)$. From these, we may conclude that (1) Berm erosion increases and bar becomes further away offshore on a beach with small sand grain; (2) Storm wave could break on the bar crest in the later stage of a storm event, which could reduce storm wave energy and limits subsequent berm erosion; (3) A larger buffer is required for beach with smaller sand grain, in order to effectively absorb storm wave energy. 


\section{REFERENCES}

Bruun, P., 1954. Coast erosion and the development of beach profiles. Tech. Memo 44, Beach Erosion Board, U.S. Army Corps of Engineers, Washington, D.C.

Dean, R. G., 1977. Equilibrium beach profiles: U. S. Atlantic, Gulf coasts. Ocean Engineering Report No.12, Department of Civil Engineering, University of Delaware, Newark, Delaware, 45 pp.

Fitzgerald, D.M., S. Vanheteren, T. M. Montello, 1994. Shoreline processes and damage resulting from the Halloween-Eve storm of 1991 along the North and South Shores of Massachusetts Bay, USA. Journal of Coastal Research, 10(1), 113-132.

Hanson, H., A. Brampton, M. Capobianco, H.H. Dette, L. Hamm, C. Laustrup, A. Lechuga, R. Spanhof, 2002. Beach nourishment projects, practices, and objectives - a European overview. Coastal Engineering, 47, 81-111.

Hisamichi, N., F. Kato, 2008. Storm surge disaster caused by Ekman transportation along Pacific Ocean side of northern part of Japan in 2006. Proc. $31^{\text {th }}$ Inter. Conf. Coastal Engineering, ASCE, vol. 2, 1098-1109.

Kraus, N. C., M. Larson, 1988. Beach profile change measured in the tank for large waves 1956-1957 and 1962. Tech. Report CERC 88-6. Coastal Engineering Research Center, US Army Corps of Engineers.

Larson, M., N. C. Kraus, M.R. Byrnes, 1990. SBEACH: Numerical model for simulating storminduced beach change, Report 2, Numerical formulation and model tests. Tech Rept. CERC 89-9. Coastal Engineering Research Center, US Army Corps of Engineers.

MAECOP (Ministry for Agriculture, Environment and Consumer Protection). 2009. Summary of Coastal Protection for Mecklenburg-Vorpommern: foundation, principles, positioning and outlook, 102 pp. [Original title in German: Minister für Landwirtschaft, Umwelt und Verbraucherschutz des Landes. 2009. Regelwerk Küstenschutz Mecklenburg-Vorpommern - Übersichtsheft: Grundlagen, Grundsätze, Standortbestimmung und Ausblick, 102 pp]

Wiegel, R.L., 1965. Oceanographical Engineering. Englewood Cliffs, NJ: Prentice Hall, 531 pp. 